\title{
SHEAR CAPACITY OF REINFORCED CONCRETE SUBJECTED TO TENSION: EXPERIMENTAL RESULTS AND ANALYSIS
}

\author{
Robert M. Foster ${ }^{1}$, Savan Haria ${ }^{2}$, Chris T. Morley ${ }^{3}$ and Janet M. Lees ${ }^{4}$
}

\begin{abstract}
This study applies a plastic approach to the analysis of shear at a joint or interface in reinforced concrete. Push-off tests have been used historically to investigate combinations of shear and compression across an interface in reinforced concrete. Recent work by the authors has shown that such tests can also be modified to model combinations of shear and tension; as is often found at critical interfaces such as joints in reinforced concrete structures. New experimental results are presented for modified push-off tests subject to a range of combinations of shear and tension. These results, along with a number of historical results reported in the literature are analysed using the upper bound theory of plasticity for interface shear. It is shown that the behaviour predicted by the upper bound theory is consistent with the new experimental results for an initially uncracked concrete interface subject to combinations of shear and tension. Effectiveness factors for the plastic analysis indicated by the experimental results are proposed.
\end{abstract}

\section{INTRODUCTION}

The accurate assessment of existing structures relies on a good understanding of structural behaviour. Where behaviour is not well understood, assessors will have little option but to be duly conservative to reflect this underlying uncertainty. The cost of assessing and strengthening deficient bridges

\footnotetext{
${ }^{1}$ Research Associate, Department of Architecture, University of Cambridge, UK. Corresponding author, email: rmf41@cam.ac.uk

${ }^{2}$ Former undergraduate student, Department of Engineering, University of Cambridge, UK

${ }^{3}$ Former Senior Lecturer, Department of Engineering, University of Cambridge, UK

${ }^{4}$ Reader in Civil Engineering, Department of Engineering, University of Cambridge, UK
} 
Authors' accepted version - Foster, R.M., Haria, S., Morley, C.T. and Lees, J.M. (2017) "Shear Capacity of Reinforced Concrete Subjected to Tension: Experimental Results and Analysis", J. Struct. Eng., 143(9), 04017085, http://dx.doi.org/10.1061/(ASCE)ST.1943-541X.0001819

structures has been estimated as being in excess of $£ 4$ billion for the UK (Middleton 2004) and \$140

billion for the US (American Association of State Highway Transportation Officials 2008).

Deficiencies in the strength of infrastructure may be actual deficiencies arising as a result of a variety of factors including: deterioration, construction defects, accidental damage, changes in understanding and failure to design for future loading. Deficiencies may also be 'theoretical' deficiencies arising as a result of uncertainty or the application of 'inappropriate' analytical approaches that are overly conservative (Shave et al. 2007). For example, a survey of UK highway bridge infrastructure (Highways Agency 2003) identified that of 272 failures by assessment of the primary structure, 73 were attributable to "conservative or inappropriate analysis", with a further 32 failures due to "particularly conservative assumptions", sometimes as a result of incomplete design information. The demolition and replacement of structures failing assessment can involve large capital expenditure; environmental impacts; lengthy interruptions to service; over-burdening of nearby infrastructure; and local opposition to construction works. Strengthening options may exist, however there may still be considerable cost involved. If a better understanding of structural behaviour can lead to an improvement in the assessment of the strength of existing structures then this is likely to be of considerable economic value.

In reinforced concrete structures the capacity of a joint or interface to transfer shear forces may be the critical consideration in assessing the capacity of the structure as a whole. Historical failures, such as the failure at a half-joint or dapped-end that precipitated the 2006 collapse of the de la Concorde overpass in Quebec (Gouvernement du Québec 2007), have highlighted the need for improved understanding of the behaviour of critical joints subject to combinations of shear and tension. While the lower bound theorem of plasticity is widely used in design of reinforced concrete, it may be advantageous to use the upper bound theory for the purposes of assessment, provided suitable values for the effectiveness of the concrete are included in the analysis (Ibell et al. 1997). This study provides experimental verification of the upper bound theorem of plasticity for the analysis of initially uncracked concrete subject to combined shear and tension. Effectiveness factors for concrete indicated by the experimental results are presented. 
Authors' accepted version - Foster, R.M., Haria, S., Morley, C.T. and Lees, J.M. (2017) "Shear Capacity of Reinforced Concrete Subjected to Tension: Experimental Results and Analysis", J. Struct. Eng., 143(9), 04017085, http://dx.doi.org/10.1061/(ASCE)ST.1943-541X.0001819

Considerable investigation has been undertaken into the capacity of a reinforced concrete joint or interface to transfer shear load, where this load transfer is described variously as shear transfer, shear friction or aggregate interlock. However, there has been very little consideration of the influence of combinations of shear and tension on the reinforced concrete behaviour. This is important because in many situations, such as at half-joints / dapped-ends, the shear plane will be subjected to a coexisting tension, either as a matter of design or as a result of unanticipated secondary effects. This study presents experimental results obtained using a 'modified' push-off testing approach to investigate combinations of shear and tension. An analysis applying the plasticity theory for shear and normal stresses at an interface is carried out. A number of experimental results reported in the literature are also analysed. The modified push-off tests presented provide new experimental validation for the use of the upper bound theory of plasticity to describe interfaces of this type, subject to combinations of shear and tension. New effectiveness factors for concrete, indicated by this research, are suggested for use in plastic analysis of joints.

\section{BASIS FOR INVESTIGATION}

\section{Experimental investigations}

The transfer of shear across an interface has been the subject of much research. Experimental investigations, notably by Hofbeck et al. (1969), Mattock \& Hawkins (1972) and Walraven \& Reinhardt (1981), have involved the use of 'push-off' tests. Conventional push-off tests (Figure 1a) are designed to elicit pure shear across an interface by forming a failure plane concentric with, and parallel to, an applied load, $F$. Roughness of the interface due to the presence of aggregate and other deviations means that, for slip of the two halves of the specimen to occur along the interface, there must be sufficient crack dilation for the opposing faces either to override (Birkeland \& Birkeland 1966), or else for the formation and rotation of diagonal 'struts' in the concrete to occur (Hofbeck et al 1969). Dilation strains any reinforcement crossing the interface and commensurate restraint forces are developed in turn. Such tests may involve an interface that is initially uncracked, meaning that no 
Authors' accepted version - Foster, R.M., Haria, S., Morley, C.T. and Lees, J.M. (2017) "Shear Capacity of Reinforced Concrete Subjected to Tension: Experimental Results and Analysis", J. Struct. Eng., 143(9), 04017085, http://dx.doi.org/10.1061/(ASCE)ST.1943-541X.0001819

visible cracking of the interface is evident at the start of the test; or initially cracked, indicating that visible cracking of the interface is evident. Initially cracked specimens have generally been subjected to a controlled pre-cracking along the interface, usually by application of a knife edge load along the edge of the intended failure plane (Hofbeck et al. 1969, Mattock \& Hawkins 1972, Walraven \& Reinhardt 1981). It is difficult in practice to establish internal crack widths in a concrete push-off specimen, meaning that the crack widths reported are typically measured externally. In the following discussion of the historical results, compressive stresses normal to the interface are denoted positive in accordance with the presentation of earlier investigators.
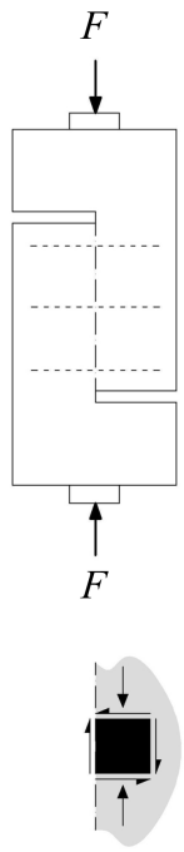

(a)
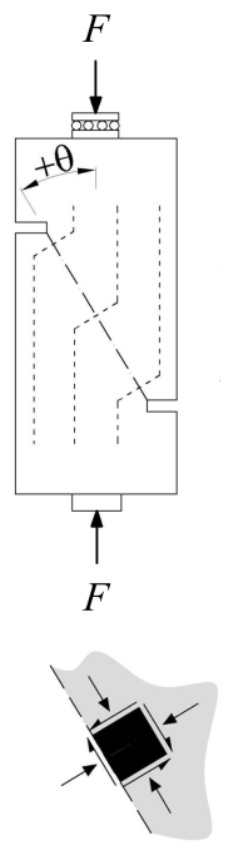

(b)
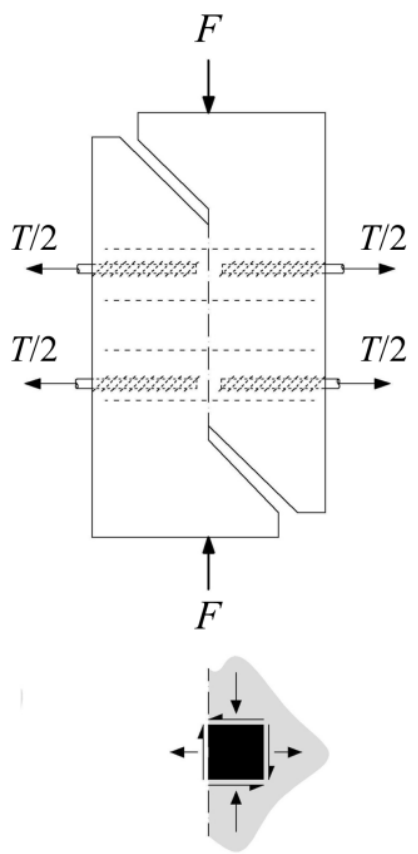

(c)

Figure 1. Push-off test arrangements and stress state at interface due to applied loads: (a) conventional; (b) modified with +ve $\theta$; (c) conventional with tension [data from Mattock and Hawkins 1972, Mattock et al. 1975]

Mattock \& Hawkins (1972) modified the conventional specimen geometry to produce a "modified" push-off specimen (Figure 1b) that induced a diagonal failure plane (at $+v e$ angles $\theta$ varying from $0^{\circ}$ to $75^{\circ}$ ) concentric with, but inclined to, the applied load $F$. This arrangement generated a failure plane subject to a combination of shear, $F \cos \theta$, and a compression, $F \sin \theta$. The average compressive normal stress due to the applied load ranged from 2.8 to $17 \mathrm{MPa}$ for specimens noted to fail in shear ( $\theta$ from 
Authors' accepted version - Foster, R.M., Haria, S., Morley, C.T. and Lees, J.M. (2017) "Shear Capacity of Reinforced Concrete Subjected to Tension: Experimental Results and Analysis", J. Struct. Eng., 143(9), 04017085, http://dx.doi.org/10.1061/(ASCE)ST.1943-541X.0001819

$8915^{\circ}$ to $45^{\circ}$ ), and from 19.2 to $27.1 \mathrm{MPa}$ for specimens noted to fail in compression ( $\theta$ from $60^{\circ}$ to $75^{\circ}$ )

90 for a range of normal strength concretes. In all cases the reinforcement was arranged perpendicular to

91 the failure plane.

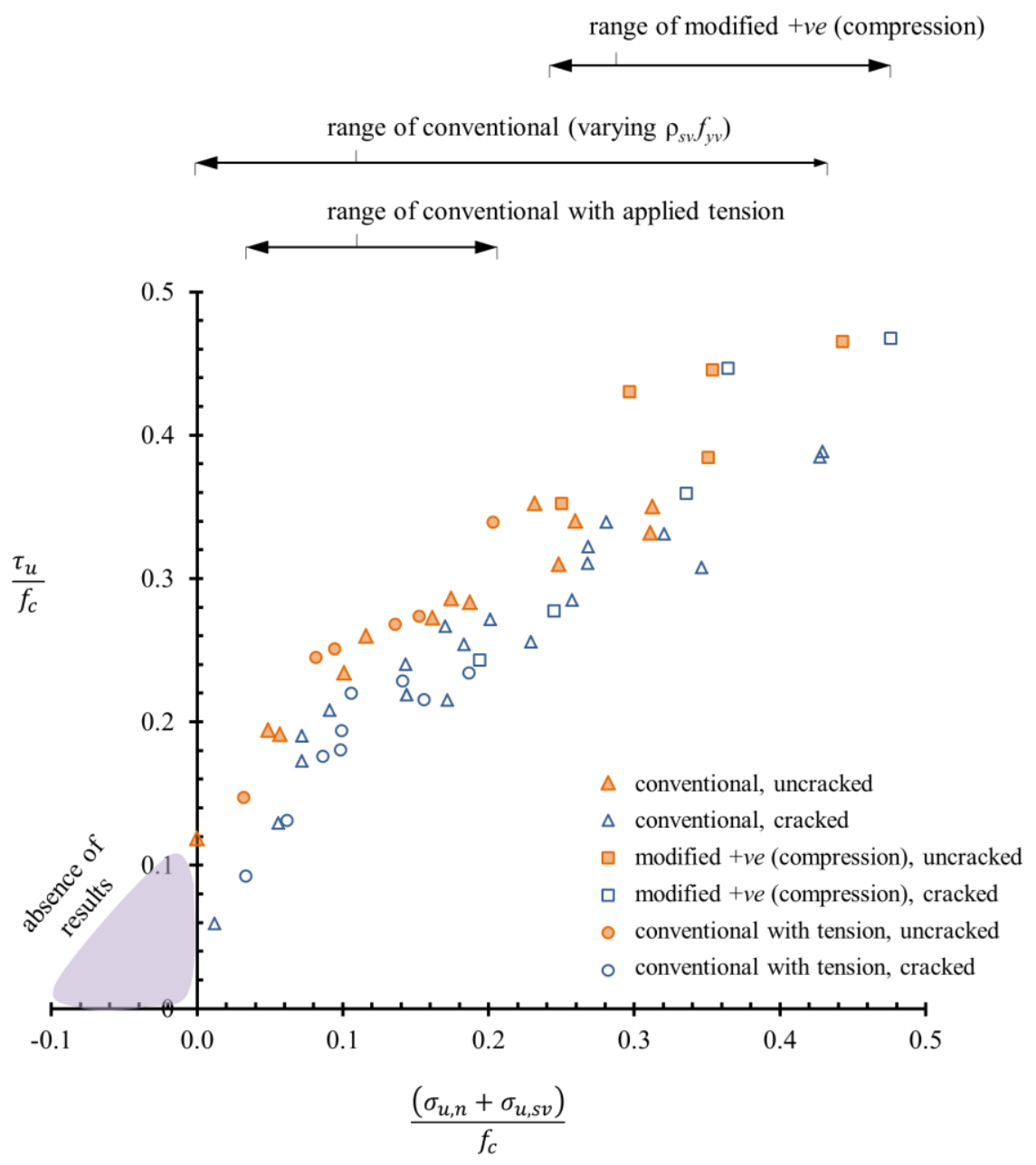

Figure 2. Normalised push-off tests results [data from Hofbeck et al. 1969, Mattock and Hawkins 1972 and Mattock et al 1975]

95 Mattock et al. (1975) performed a series of conventional push-off tests with embedded bars perpendicular to the interface, allowing tension $T$ to be generated across the failure plane (Figure $1 \mathrm{c}$ ).

97 These tests were carried out with a range of fixed tensions applied, giving an constant average tensile 98 normal stress across the shear plane of between -0.7 and $-2.8 \mathrm{MPa}$. The specimens were then 99 subjected to increasing shear load. At peak load $F_{u}$ the restraint stress provided by the reinforcement, 
Authors' accepted version - Foster, R.M., Haria, S., Morley, C.T. and Lees, J.M. (2017) "Shear Capacity of Reinforced Concrete Subjected to Tension: Experimental Results and Analysis", J. Struct. Eng., 143(9), 04017085, http://dx.doi.org/10.1061/(ASCE)ST.1943-541X.0001819

which was noted to yield, was greater than the applied tension; indicating that the net normal force on the interface was compressive.

Figure 2 summarises normalised push-off test results carried out by Hofbeck et al. (1969), Mattock \& Hawkins (1972), and Mattock et al. (1975). The mean concrete compressive cylinder strength is $f_{c}$. The nominal average ultimate shear stress on the shear plane of area $A$ is $\tau_{u}$ where:

$\tau_{u}=\frac{F_{u} \cos \theta}{A}$ Equation 1

105

Assuming yielding of the reinforcement, the confining stress normal to the shear plane due to the 106 restraining effect of the internal steel of area $A_{s v}$ and yield strength $f_{y v}$ is $\sigma_{u, s v}$ :

$\sigma_{u, s v}=\frac{\mathrm{A}_{s v} f_{y v}}{A}$

Equation 2

107 The externally applied stress (compression $+v e$ ) normal to the shear plane is $\sigma_{u, n}$. For the modified 108 push-off tests:

$\sigma_{u, n}=\frac{F_{u} \sin \theta}{A}$

Equation 3 and for the conventional tests with a tensile force $-T$ applied normal to the shear plane through embedded bars:

$\sigma_{u, n}=\frac{-T}{A}$

Equation 4

111 Significant overlap can be seen between the series with respect to the total restraint stress across the

112 interface presented as the sum of varying combinations of $\sigma_{u, n}$ and $\sigma_{u, s v}$. Broadly speaking, initially 113 uncracked specimens achieve higher normalised shear strengths than cracked specimens for similar 114 normalised restraint stresses. The modified specimens with $+v e \theta$ (compression) and the conventional 115 specimens with tension show relatively good agreement with the conventional results, indicating that 116 the superposition of moderate normal stresses with the passive restraint stresses due to the 
Authors' accepted version - Foster, R.M., Haria, S., Morley, C.T. and Lees, J.M. (2017) "Shear Capacity of Reinforced Concrete Subjected to Tension: Experimental Results and Analysis", J. Struct. Eng., 143(9), 04017085, http://dx.doi.org/10.1061/(ASCE)ST.1943-541X.0001819

117 reinforcement is not unreasonable. However, in the region in which a net tension is present across the 118 shear plane, there is an absence of experimental results. This is significant because, although the 119 contribution of concrete tensile strength is typically neglected in strength design, the pattern of results indicates potential non-zero shear strength in this region for an initially uncracked interface. This study therefore presents results obtained from new, modified push-off specimens with $-v e \theta$ (tension) in order to provide empirical data that allows theoretical understanding to be evaluated across the full range of values illustrated in Figure 2. However, it is necessary to first consider the theory.

\section{Existing models for shear transfer at an interface}

138 Although a dowel contribution was recognised, it was thought to be implicitly accounted for by the "fictitiously high" (Mattock \& Hawkins 1972) coefficient of friction inferred from the experimental 
Authors' accepted version - Foster, R.M., Haria, S., Morley, C.T. and Lees, J.M. (2017) "Shear Capacity of Reinforced Concrete Subjected to Tension: Experimental Results and Analysis", J. Struct. Eng., 143(9), 04017085, http://dx.doi.org/10.1061/(ASCE)ST.1943-541X.0001819

140 results. The fib model code (fib 2010) also indicates that mechanical interlock and adhesion can be 141 expected to contribute primarily when slip displacements are very small, but that for larger slip 142 displacements these effects are likely to be substantially reduced. As a result, two governing shear transfer modes are posited in the fib model code: rigid bond-slip behaviour associated with dominance of the adhesion/interlock mechanism; and non-rigid bond-slip behaviour associated with dominance of the frictional and dowel mechanisms (fib 2010). Thus it may be inferred that adhesion/interlock is likely to be either the dominant mechanism, as in the rigid bond-slip condition, or else a rather small or even negligible contributor in the non-rigid bond slip case.

Shear transfer models implicitly allow for permanent compressive normal stresses across an interface to be superposed with the clamping force of the reinforcement, for the purposes of calculating the normal force associated with the frictional component of resistance. The validity of this superposition for moderate compressive stresses was shown experimentally by Mattock and Hawkins (1972). However, shear friction models typically tend to zero shear strength as confining compressive stresses reduce to zero, as in the friction-only model of Birkeland \& Birkeland (1966) and the frictioninterlock-dowel model of ACI318 (ACI 2014). Alternatively, where models imply that shear strength may be non-zero when normal stresses are zero, there is a cut-off specified in the case of net tension, as in the models of EC2 (BSI 2004) and the fib model code (fib 2010). The modelling of actual behaviour in the presence of coexisting normal tensile stresses therefore presents a challenge to these models. While the assumption of zero shear strength in the presence of tension may be appropriate for the purposes of interface design, shear friction models do not appear to be suitable for the investigation of the actual strength of initially uncracked concrete in the presence of a net tensile normal stress.

\section{Plastic analysis of shear transfer at an interface}

163 An alternative approach to the analysis of shear transfer at a cracked and uncracked concrete interface is provided by the upper bound theory of plasticity. Cracked in this context is taken to mean concrete having cracks visible to the naked eye, or a crack width of approximately $0.1 \mathrm{~mm}$ (Neville 2011). 
Authors' accepted version - Foster, R.M., Haria, S., Morley, C.T. and Lees, J.M. (2017) "Shear Capacity of Reinforced Concrete Subjected to Tension: Experimental Results and Analysis", J. Struct. Eng., 143(9), 04017085, http://dx.doi.org/10.1061/(ASCE)ST.1943-541X.0001819

Where specimens are reported in the literature as being pre-cracked or visible cracking is reported prior to loading, the interface is assumed to be cracked; otherwise the interface is assumed to be uncracked. The theory for an uncracked interface in monolithic concrete was developed by Jensen (1977). Identical solutions were obtained by Chen (1988). An upper bound analysis of a test series of conventional push-off specimens with an initially uncracked interface with steel transverse reinforcement was carried out by Ibell \& Burgoyne (1999) assuming an S-shaped shear plane. Jensen (1977) also presented a plastic analysis for a cracked interface, assuming plane strain conditions such that sliding is assumed in the plane of the interface and using ad hoc effectiveness factors relating to particular experimental results. The application of the theory to cracked concrete was further developed by Zhang (1997) with the more general treatment of the reduced effectiveness of concrete due to reduced concrete cohesion along a cracked failure plane. Comprehensive treatment of the background and derivations to these approaches are provided elsewhere by Nielsen \& Hoang (2011).

The following assumptions are made here in applying the upper bound theory of plasticity to the behaviour of interfaces in reinforced concrete:

1. Perfectly plastic material behaviour is assumed such that strains prior to yielding of the material are negligible, and strains thereafter may be arbitrarily large.

2. An effectiveness factor $v$ for concrete in compression is applied such that the effective concrete strength in compression is $v f_{c}$, where $f_{c}$ is the uniaxial concrete compressive cylinder strength. This is intended to account for a number of effects including softening, microcracking and local stress concentrations (Nielsen \& Hoang 2011).

3. A further effectiveness factor $v_{s}$ is applied to the strength of cracked concrete such that the effective strength of cracked concrete against 'sliding' is $v_{s} v f_{c}$. This accounts for the reduced yield strength of concrete along a cracked plane. A value of 0.5 is adopted for $v_{s}$, following Zhang (1997).

4. A Modified-Coulomb failure criterion for concrete is adopted. The concrete is treated as a granular material with a friction angle $\varphi$ of $37^{\circ}$ under all combinations of stress (Nielsen \& 
Authors' accepted version - Foster, R.M., Haria, S., Morley, C.T. and Lees, J.M. (2017) "Shear Capacity of Reinforced Concrete Subjected to Tension: Experimental Results and Analysis", J. Struct. Eng., 143(9), 04017085, http://dx.doi.org/10.1061/(ASCE)ST.1943-541X.0001819

Hoang 2011). The value of $\varphi$ is assumed to be the same for both uncracked and cracked concrete (Zhang 1997). A limiting concrete tensile strength $f_{t}$ is assumed to account for the possibility of separation failure. The value of $f_{t}$ is taken as $v_{t} v f_{c}$, where $v_{t}$ is a further effectiveness factor for concrete in tension.

5. Steel reinforcing bars are assumed to carry only axial forces and yield at stress $f_{y v}$. Dowel action of reinforcement is not explicitly considered, although its influence will be to some extent implicit in any values of effectiveness factors inferred from experimental results.

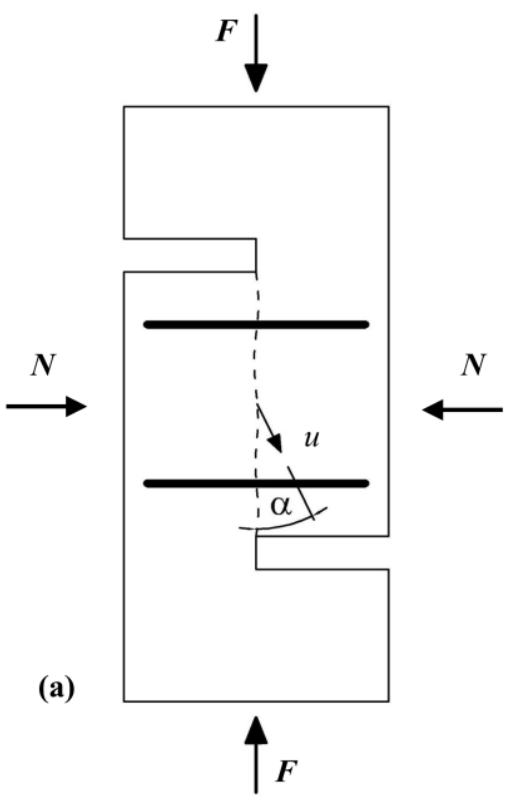

(b)

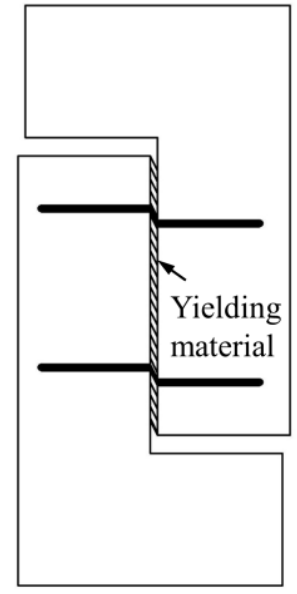

Figure 3. Conventional push-off test as an example of an interface subject to shear: (a) with displacement vector $u$ at angle $\alpha$ to the applied load; (b) highlighting the deformation due to yielding of material at the interface

Two cases are thus considered in the following analyses in relation to the transfer of shear across an interface in reinforced concrete:

1. An initially uncracked interface in which the effective yield strength of the concrete material is the same in all directions;

2. An initially cracked interface in which the effective yield strength of the concrete is reduced in the plane of the cracked interface. 
Authors' accepted version - Foster, R.M., Haria, S., Morley, C.T. and Lees, J.M. (2017) "Shear Capacity of Reinforced Concrete Subjected to Tension: Experimental Results and Analysis", J. Struct. Eng., 143(9), 04017085, http://dx.doi.org/10.1061/(ASCE)ST.1943-541X.0001819

$$
\psi=\frac{\rho_{s v} f_{y v}}{v f_{c}}
$$$$
\psi^{*}=\psi+\frac{N}{A v f_{c}}
$$

The external work $W_{E}$ done by the applied loads is the sum of the work done by the applied load $F$ in the vertical direction and the work done against the restraint force $N$ normal to the interface;

$W_{E}=F u \cos \alpha-N u \sin \alpha$ Equation 9

224 The energy dissipated by the yielding reinforcement $W_{I, r}$, assumed to be axial and neglecting dowel action is;

$W_{I, r}=A_{s v} f_{y v} u \sin \alpha$ Equation 10 
Authors' accepted version - Foster, R.M., Haria, S., Morley, C.T. and Lees, J.M. (2017) "Shear Capacity of Reinforced Concrete Subjected to Tension: Experimental Results and Analysis", J. Struct. Eng., 143(9), 04017085, http://dx.doi.org/10.1061/(ASCE)ST.1943-541X.0001819

226 The energies dissipated by the yielding concrete $W_{I, c}$ for displacements at angles $\alpha$ relative to the

227 interface of less than, equal to, or greater than, the friction angle $\varphi$ are;

$W_{I, c}=\frac{1}{2} \nu f_{c} u(1-\sin \alpha) A$ for $0<\alpha \leq \varphi$

Equation 11

$W_{I, c}=\frac{1}{2} v f_{c} u(1-\sin \varphi) A$ for $\alpha=\varphi$

Equation 12

$W_{I, c}=\left(\frac{1}{2} v f_{c}(1-\sin \alpha)+\left(\frac{\sin \alpha-\sin \varphi}{1-\sin \varphi} v_{t} v f_{c}\right)\right) u A$ for $\alpha>\varphi$

Equation 13

228 for an arrangement analogous to that shown in Figure 3. Note that for $\alpha>$ the friction angle $\varphi$, there is

229 a component of dissipation due to separation of the concrete, governed by the effective concrete

230 strength in tension $v_{t} v f_{c}$. If the effective concrete tensile strength is assumed to be negligible, i.e. $v_{t}=$

2310 , then no energy is dissipated by the concrete in tension and Equation 13 reduces to Equation 11.

232 Thus minimising for $\tau / f_{c}$, for an uncracked interface in monolithic concrete, Nielsen and Hoang (2011)

233 show that:

$\frac{\tau}{f_{c}}=\sqrt{\left(\psi^{*}+v_{t}\right)\left[v-2 v_{t} \frac{\sin \varphi}{1-\sin \varphi}\right]-\left(\psi^{*}+v_{t}\right)}$

Equation 14

234 for,

$\psi^{*} \leq v \frac{1-\sin \varphi}{2}-v_{t}(1+\sin \varphi)$

Equation 15

235 and,

$\frac{\tau}{f_{c}}=v \frac{1-\sin \varphi}{2 \cos \varphi}+\psi^{*} \tan \varphi$

Equation 16

236 for, 
Authors' accepted version - Foster, R.M., Haria, S., Morley, C.T. and Lees, J.M. (2017) "Shear Capacity of Reinforced Concrete Subjected to Tension: Experimental Results and Analysis", J. Struct. Eng., 143(9), 04017085, http://dx.doi.org/10.1061/(ASCE)ST.1943-541X.0001819

$v \frac{1-\sin \varphi}{2}-v_{t}(1+\sin \varphi) \leq \psi^{*} \leq v \frac{1-\sin \varphi}{2}$

Equation 17

237 and,

$\frac{\tau}{f_{c}}=\sqrt{\psi^{*}\left(v-\psi^{*}\right)}$

Equation 18

238 for,

$v \frac{1-\sin \varphi}{2} \leq \psi^{*} \leq \frac{v}{2}$

Equation 19

239 and,

$\frac{\tau}{f_{c}}=\frac{\nu}{2}$

Equation 20

240 for,

$\psi^{*} \geq \frac{v}{2}$

Equation 21

241 Equation 20 provides a limiting shear strength occurring when $\alpha=0$. In this case the displacement

242 vector $u$ is parallel to the interface with no component of displacement in the axial direction of the

243 transverse reinforcement, meaning that all energy dissipation is by yielding of the concrete. Such an

244 interface can thus be thought of as locked-up or over-reinforced, as observed experimentally by

245 Mattock \& Hawkins (1972).

\section{Cracked concrete interface}

247 In a similar manner, the work done and energy dissipated can be equated for an arrangement 248 analogous to that shown in Figure 3 for a cracked interface. This condition may occur at a joint or at a 249 pre-existing macro-crack in the web of a concrete beam. For a cracked interface, conditions of plane strain are assumed such that the angle $\alpha$ of the displacement vector $u$ is not less than the friction angle 
Authors' accepted version - Foster, R.M., Haria, S., Morley, C.T. and Lees, J.M. (2017) "Shear Capacity of Reinforced Concrete Subjected to Tension: Experimental Results and Analysis", J. Struct. Eng., 143(9), 04017085, http://dx.doi.org/10.1061/(ASCE)ST.1943-541X.0001819

$\varphi$. Nielsen and Hoang (2011) show that minimising for $\tau / f_{c}$ and incorporating the effectiveness factor

$252 v_{s}$ for the reduced strength of cracked concrete gives:

$$
\frac{\tau}{f_{c}}=\sqrt{\left(\psi^{*}+v_{s} v_{t}\right)\left[v_{s} v-2 v_{s} v_{t} \frac{\sin \varphi}{1-\sin \varphi}\right]-\left(\psi^{*}+v_{s} v_{t}\right)}
$$

253 for,

$\psi^{*} \leq v_{s} v \frac{1-\sin \varphi}{2}-v_{s} v_{t}(1+\sin \varphi)$

Equation 23

254 and,

$\frac{\tau}{f_{c}}=v_{s} v \frac{1-\sin \varphi}{2 \cos \varphi}+\psi^{*} \tan \varphi$

Equation 24

255 for,

$\psi^{*} \geq v_{s} v \frac{1-\sin \varphi}{2}-v_{s} v_{t}(1+\sin \varphi)$

Equation 25

256 The capacity of the cracked interface is subject to the further limiting condition that it cannot exceed

257 the capacity of an uncracked interface. This condition is logical since there is no reason why a cracked plane should be stronger than uncracked material and, in any such case, failure would simply be expected to occur through the uncracked material immediately adjacent to the cracked plane. This condition is also in accordance with the observations of Mattock \& Hawkins (1972) that there was no difference in the shear capacity of initially cracked and initially uncracked specimens with high levels of transverse reinforcement or subject to large compressive normal stresses.

The equations of the plastic analysis lead to the non-dimensional shear capacity envelopes drawn in Figure 4. The envelopes for cracked and uncracked interfaces are shown for $v_{t}=0$, assuming that the effective strength of concrete in tension is negligible; and for $v_{t}>0$, assuming that the effective concrete strength in tension is non-zero but small compared to the effective concrete strength in 
Authors' accepted version - Foster, R.M., Haria, S., Morley, C.T. and Lees, J.M. (2017) "Shear Capacity of Reinforced Concrete Subjected to Tension: Experimental Results and Analysis", J. Struct. Eng., 143(9), 04017085, http://dx.doi.org/10.1061/(ASCE)ST.1943-541X.0001819

267

268

269

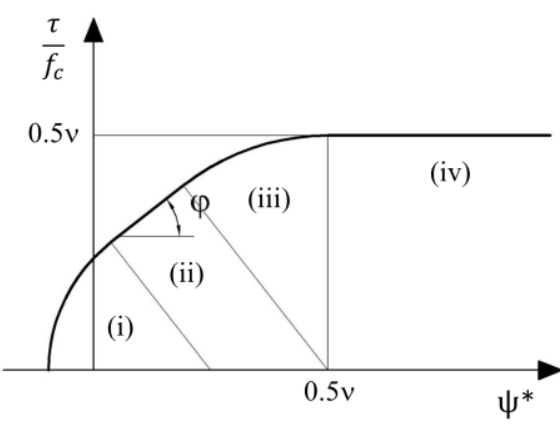

(a) uncracked interface, $v_{t}>0$

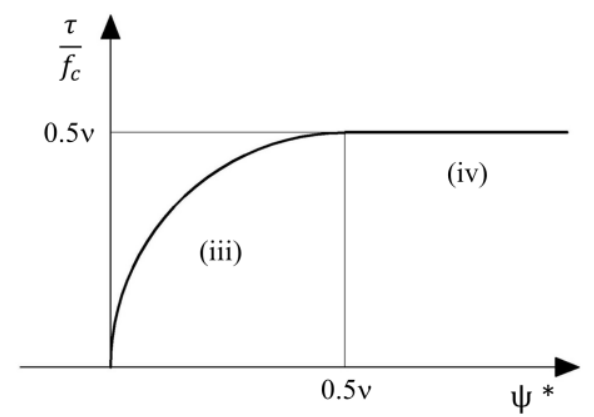

(c) uncracked interface, $v_{t}=0$

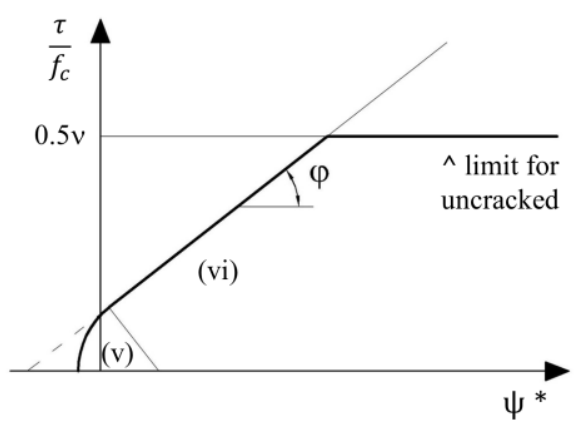

(b) cracked interface, $v_{t}>0$

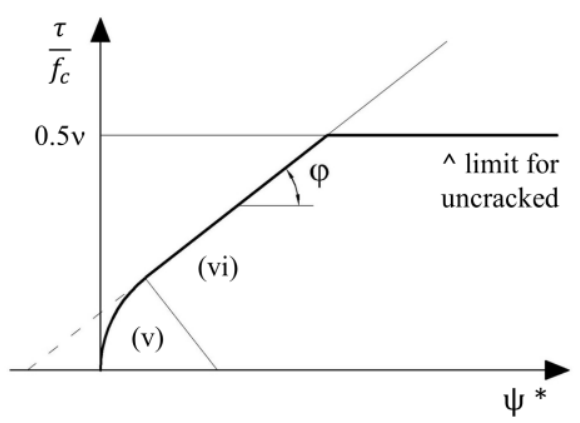

(d) cracked interface, $v_{t}=0$

Figure 4. Non-dimensional shear capacity envelopes for uncracked and cracked interfaces for $v_{t}>0$ and $v_{t}=0$

\section{Comparison with results from the literature}

Chen (1988) proposed effectiveness factors for concrete of $v=0.665$ and $v_{t}=0.035$ for the upper bound plastic analysis of an uncracked interface based on comparison with the conventional push-off testing results of Hofbeck et al. (1969). Chen did not carry out a commensurate analysis for a cracked 
Authors' accepted version - Foster, R.M., Haria, S., Morley, C.T. and Lees, J.M. (2017) "Shear Capacity of Reinforced Concrete Subjected to Tension: Experimental Results and Analysis", J. Struct. Eng., 143(9), 04017085, http://dx.doi.org/10.1061/(ASCE)ST.1943-541X.0001819

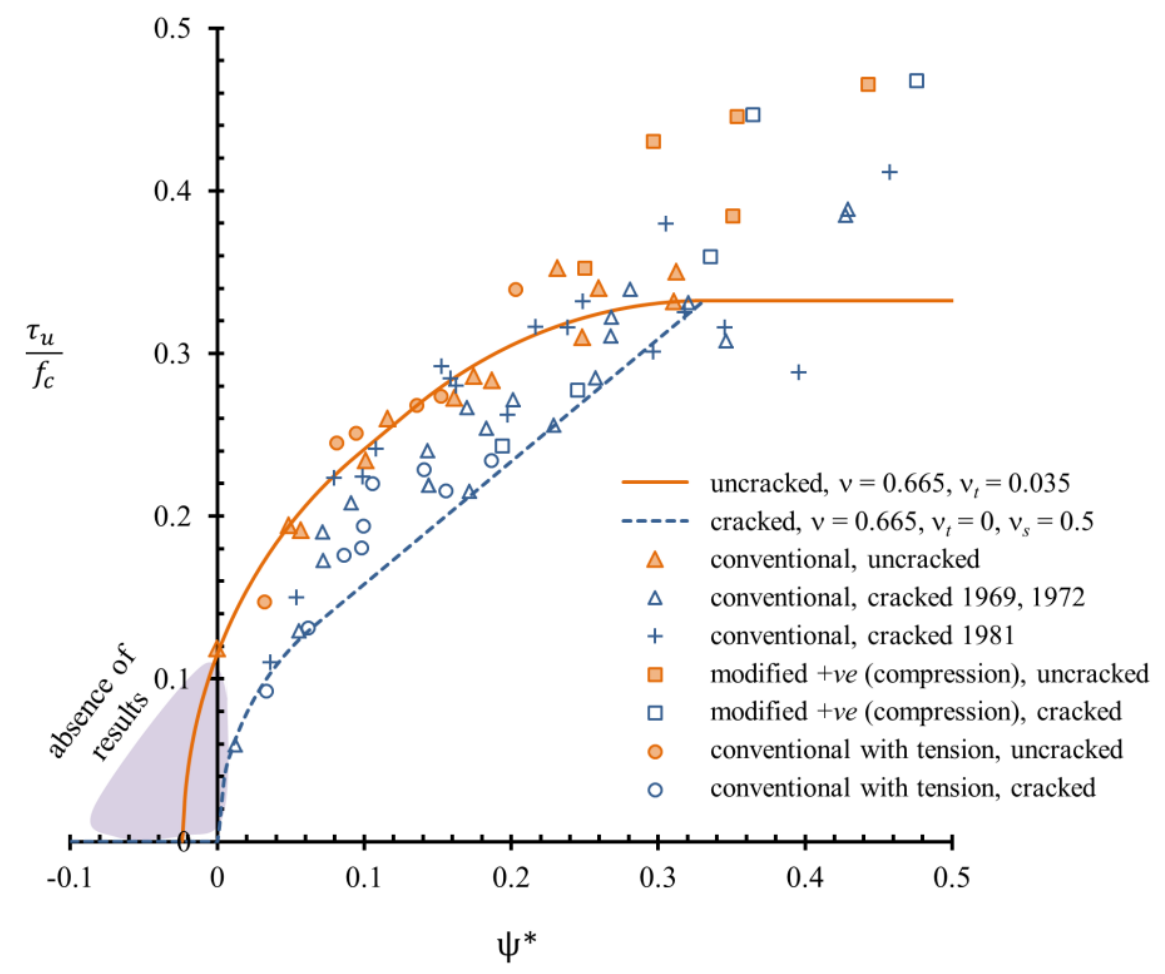
cracked analysis, compared with a range of push-off test results in the literature

Also shown in Figure 5 is an expanded data set of initially uncracked and initially cracked: conventional push-off test results from Hofbeck et al (1969) and Walraven \& Reinhardt (1981); modified push-off tests with compression by Mattock and Hawkins (1972); and conventional push-off tests with tension from Mattock et al. (1975). Relatively good agreement is seen for the uncracked analysis for the range of applied compressive and tensile normal stresses used in these tests, although the concrete effectiveness is underestimated at higher levels of compression. This underestimation is most likely a result of increased confinement due to the strong compression field. There is a notable absence of experimental results provided in the literature for the region $\psi^{*}<0$, indicating an absence of verification of the plastic theory in this region. Although there is considerable scatter, the cracked analysis generally provides a good lower bound on values until a $\psi^{*}$ of approximately 0.3 is reached. 
Authors' accepted version - Foster, R.M., Haria, S., Morley, C.T. and Lees, J.M. (2017) "Shear Capacity of Reinforced Concrete Subjected to Tension: Experimental Results and Analysis", J. Struct. Eng., 143(9), 04017085, http://dx.doi.org/10.1061/(ASCE)ST.1943-541X.0001819

Many of Walraven and Reinhardt's 1981 initially cracked test results follow the uncracked curve more closely than the cracked curve, particularly in the range $0.1<\psi^{*}<0.3$. This may indicate that the pre-cracking procedure in this case led to internal crack widths smaller than those measured at the concrete surface.

It would appear that there is an absence of experimental results for push-off specimens with a shear plane subjected to a coexisting net tension. However, the upper bound plastic analysis (Figure 5) indicates that, for an interface that is not initially cracked and having transverse reinforcement normal to the failure plane, there is potentially non-zero shear strength in the region of net tension. An experimental programme was carried out as part of this study in order to investigate actual behaviour in this region.

\section{Specimen design}

In order to investigate the case of a net tension across the shear plane comparable to the modified push off testing approach of Mattock \& Hawkins (1972), a failure plane at a $-v e$ angle $\theta$ is required. A modification to the geometry of the push-off specimen (Figure 6) was thus developed previously by the authors (Foster et al. 2016) in order to generate an interface subject to a combination of shear, $F \cos \theta$, and tensile normal force, $F \sin \theta$ and a number of specimens with $\theta=-45^{\circ}$ were tested.

The experimental programme described below extends this approach to specimens with a range of values of $-v e$ values of $\theta$ in order to provide experimental evidence of the effect of varying combinations of shear and tension on the interface.

\section{Test programme}

Seven reinforced concrete modified push-off specimens with a range of -ve values of $\theta$ were used in this study (Figure 7). The breadth (being the dimension into the page for Figure 7) of all specimens was $250 \mathrm{~mm}$. The geometry of the specimen was varied to obtain the desired failure plane inclination. 
Authors' accepted version - Foster, R.M., Haria, S., Morley, C.T. and Lees, J.M. (2017) "Shear Capacity of Reinforced Concrete Subjected to Tension: Experimental Results and Analysis", J. Struct. Eng., 143(9), 04017085, http://dx.doi.org/10.1061/(ASCE)ST.1943-541X.0001819

The applied load in all cases was aligned concentric with the shear plane, which had length $200 \mathrm{~mm}$ and breadth $250 \mathrm{~mm}$ for all specimens. For the end blocks, substantial deformed high yield internal reinforcement was provided to carry forces through the two halves of the specimen and to ensure failure through the plane under investigation. This reinforcement did not cross the shear plane. The full end block details for specimens with $\theta=-45^{\circ}$ are reported by Foster et al. (2016). The end block details for the specimens with $\theta=-37.5^{\circ},-30^{\circ},-22.5^{\circ}$ and $-15^{\circ}$ used in this study were detailed in a similar manner.
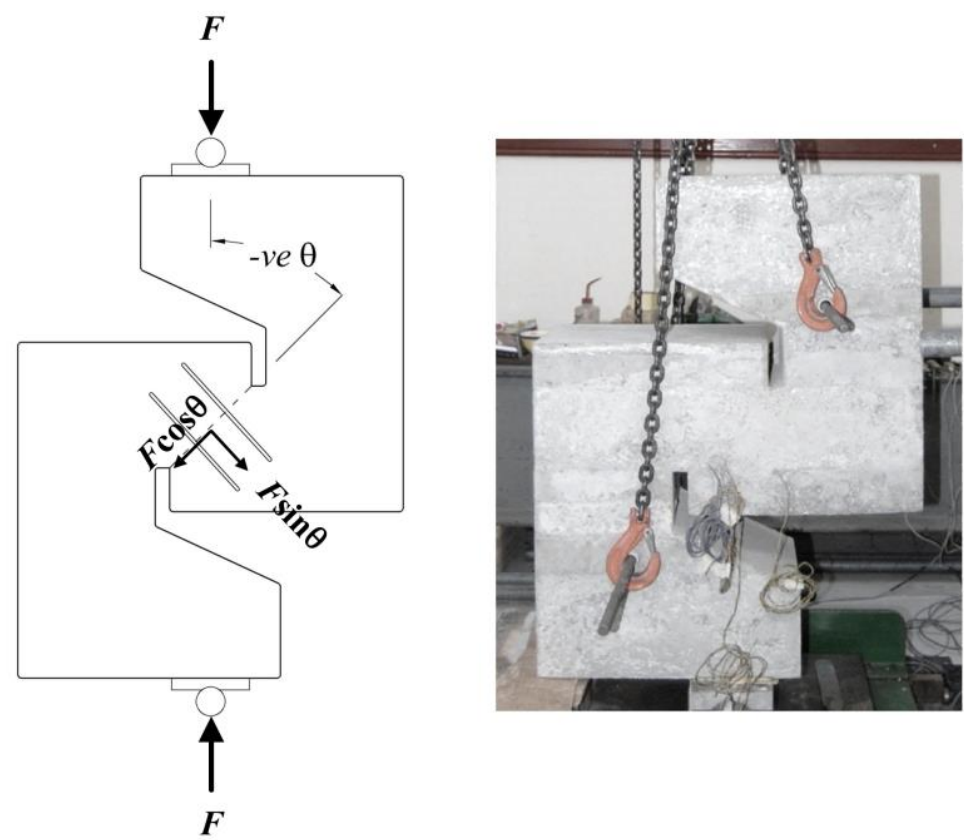

Figure 6. Modified push-off test with -ve angle $\theta$ of the type used for this investigation

The internal steel test reinforcement crossing the shear plane was $6 \mathrm{~mm}$ diameter deformed high yield bar, in the form of full stirrups oriented perpendicular to the shear plane. The transverse reinforcement area and spacing of $65 \mathrm{~mm}$ (Figure 7) was the same for all specimens, giving a $\rho_{s v}=0.23 \%$. The material properties for the stirrup steel obtained by direct tensile testing were: a Young's modulus of $203 \mathrm{GPa}$, a $0.1 \%$ offset yield strength $f_{y v}$ of $600 \mathrm{MPa}$ and an ultimate tensile strength of $648 \mathrm{MPa}$. Strain gauges were affixed to each leg of the steel test reinforcement approximately at the position of the anticipated failure plane. Strain gauging of reinforcement local to the failure plane can affect the local bond of the reinforcement and may therefore influence secondary transfer mechanisms, such as 
Authors' accepted version - Foster, R.M., Haria, S., Morley, C.T. and Lees, J.M. (2017) "Shear Capacity of Reinforced Concrete Subjected to Tension: Experimental Results and Analysis", J. Struct. Eng., 143(9), 04017085, http://dx.doi.org/10.1061/(ASCE)ST.1943-541X.0001819

those posited by Walraven and Reinhardt (1981), that might result from crack bridging. However, for the purposes of the present study it was preferable to measure strains as close to the failure plane as possible in order to obtain accurate restraint forces across the interface.
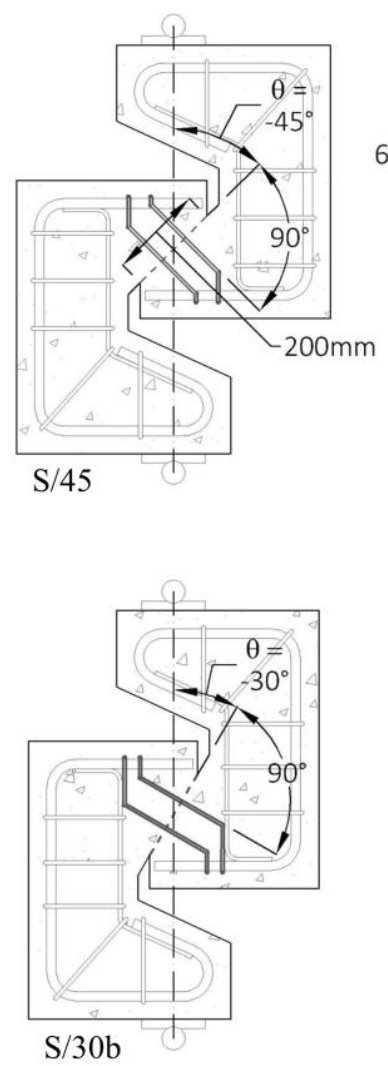
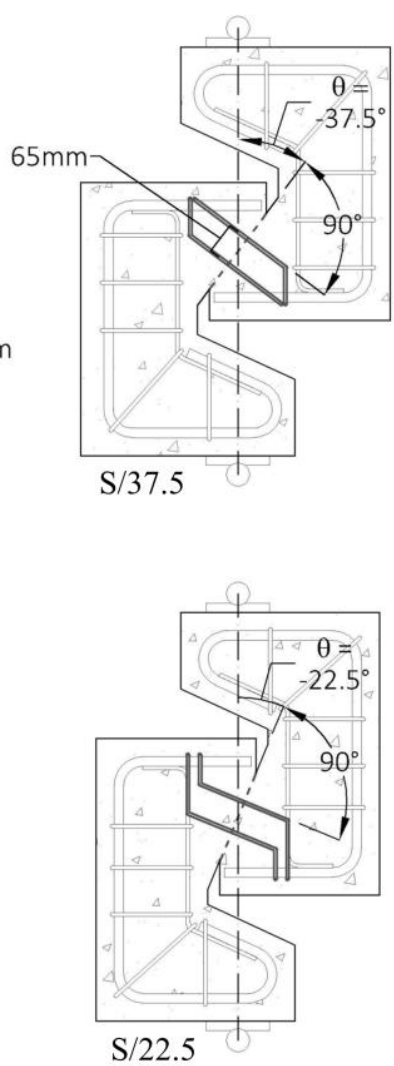
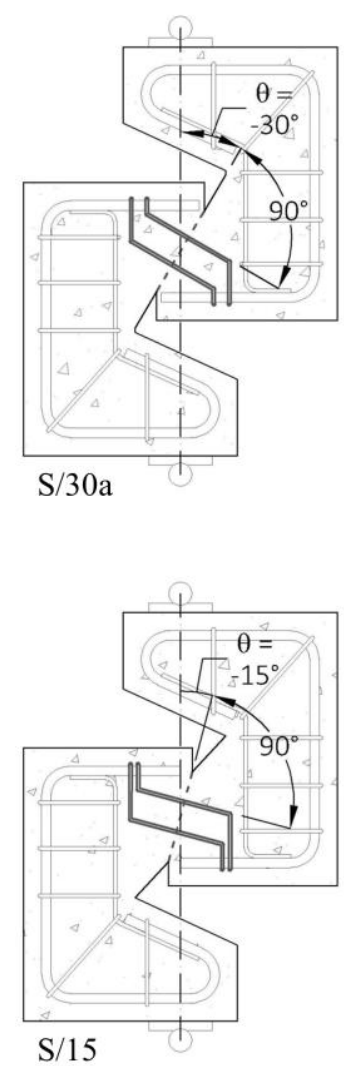

Figure 7. Modified push-off test arrangements; specimen geometry varies to obtain the intended failure plane inclination; in all cases the shear plane is $200 \times 250 \mathrm{~mm}$; transverse reinforcement crosses the shear plane at $90^{\circ}$ and the reinforcement area and spacing are the same in each specimen

The concrete mix consisted of local coarse aggregate (12 mm maximum size), fine aggregate and ordinary Portland cement (CEM II 32.5). Concrete $100 \mathrm{~mm}$ cube compressive strengths at testing are shown in Table 1 . The specimens were cast on their sides in timber formwork which was removed approximately 24 hours after casting. Specimens were then cured in air alongside their respective test cubes at ambient laboratory temperature.

Specimens were loaded concentrically through pinned supports in a $5000 \mathrm{kN}$ Amsler column testing rig. Tests were operated under displacement control. Each test began with specimens initially uncracked and loaded until peak load associated with cracking of the shear plane was reached and a 
Authors' accepted version - Foster, R.M., Haria, S., Morley, C.T. and Lees, J.M. (2017) "Shear Capacity of Reinforced Concrete Subjected to Tension: Experimental Results and Analysis", J. Struct. Eng., 143(9), 04017085, http://dx.doi.org/10.1061/(ASCE)ST.1943-541X.0001819

354

drop in load was observed. This load is considered to be the capacity of the 'uncracked' specimen and is denoted $F_{u}$. The specimen would then be substantially unloaded before being reloaded in order to observe the behaviour of the cracked shear plane. The peak load obtained during reloading is considered to be the capacity of the 'cracked' specimen and is denoted $F_{u, c r}$. This methodology differs somewhat from the knife-edged pre-cracking methodologies reported in the literature and has two distinct advantages: the first being the improved economy of testing due to the ability to obtain an uncracked and a cracked capacity from a single specimen; the second being that the 'pre-cracking' is applied in the same manner as the actual anticipated loading rather than by a separate and somewhat unrealistic transverse loading case. A disadvantage of approach adopted here is that the width of the initial crack is not controlled.

Table 1: Test specimens

\begin{tabular}{lccc}
\hline Specimen & $\begin{array}{c}f_{c u} \\
{[\mathrm{MPa}]}\end{array}$ & $\theta$ & $\begin{array}{c}\rho_{s v} \\
\%\end{array}$ \\
\hline $\mathrm{S} / 45$ & 50.9 & $-45.0^{\circ}$ & 0.23 \\
$\mathrm{~S} / 37.5$ & 64.5 & $-37.5^{\circ}$ & 0.23 \\
$\mathrm{~S} / 30 \mathrm{a}$ & 58.2 & $-30.0^{\circ}$ & 0.23 \\
$\mathrm{~S} / 30 \mathrm{~b}$ & 66.4 & $-30.0^{\circ}$ & 0.23 \\
$\mathrm{~S} / 22.5$ & 62.4 & $-22.5^{\circ}$ & 0.23 \\
$\mathrm{~S} / 15$ & 57.1 & $-15.0^{\circ}$ & 0.23 \\
\hline
\end{tabular}
EXPERIMENTAL RESULTS AND DISCUSSION

Figure 8 shows the load $F$ plotted against the vertical displacement of the whole specimen measured platen-to-platen. The unloading phase is omitted for here for clarity. The full load-displacement curve is included in the test data associated with this paper. Initial loading of the uncracked specimen elicited approximately linear elastic behaviour in the specimen prior to peak uncracked load $F_{u}$ followed by initial cracking of the shear plane and an abrupt drop in load. Specimens were then unloaded to below approximately $20 \mathrm{kN}$ (not shown) before reloading. Upon reloading the cracked shear plane displayed linear behaviour until a displacement approximately equal to that previously 
Authors' accepted version - Foster, R.M., Haria, S., Morley, C.T. and Lees, J.M. (2017) "Shear Capacity of Reinforced Concrete Subjected to Tension: Experimental Results and Analysis", J. Struct. Eng., 143(9), 04017085, http://dx.doi.org/10.1061/(ASCE)ST.1943-541X.0001819

reached at cracking, but at a reduced load. Progressive reduction in stiffness was then observed with increasing load until the peak load sustained by the cracked specimen $F_{u, c r}$ was reached. More ductile behaviour was seen after cracking for the specimens with a less vertical crack inclination. The behaviour of S/15 after cracking did not appear to correspond with the trend of increasing postcracked strength with more vertical crack inclination observed in the other tests. The shear plane formed in this specimen deviated from the intended position quite considerably, indicating that the non-test portion of the specimen design was not entirely suitable for this inclination. However, given that by definition the intended failure plane cannot have been less strong than the deviated plane taken, the stress state at the intended failure plane thus remains useful data for evaluating the upper bound plastic analysis.

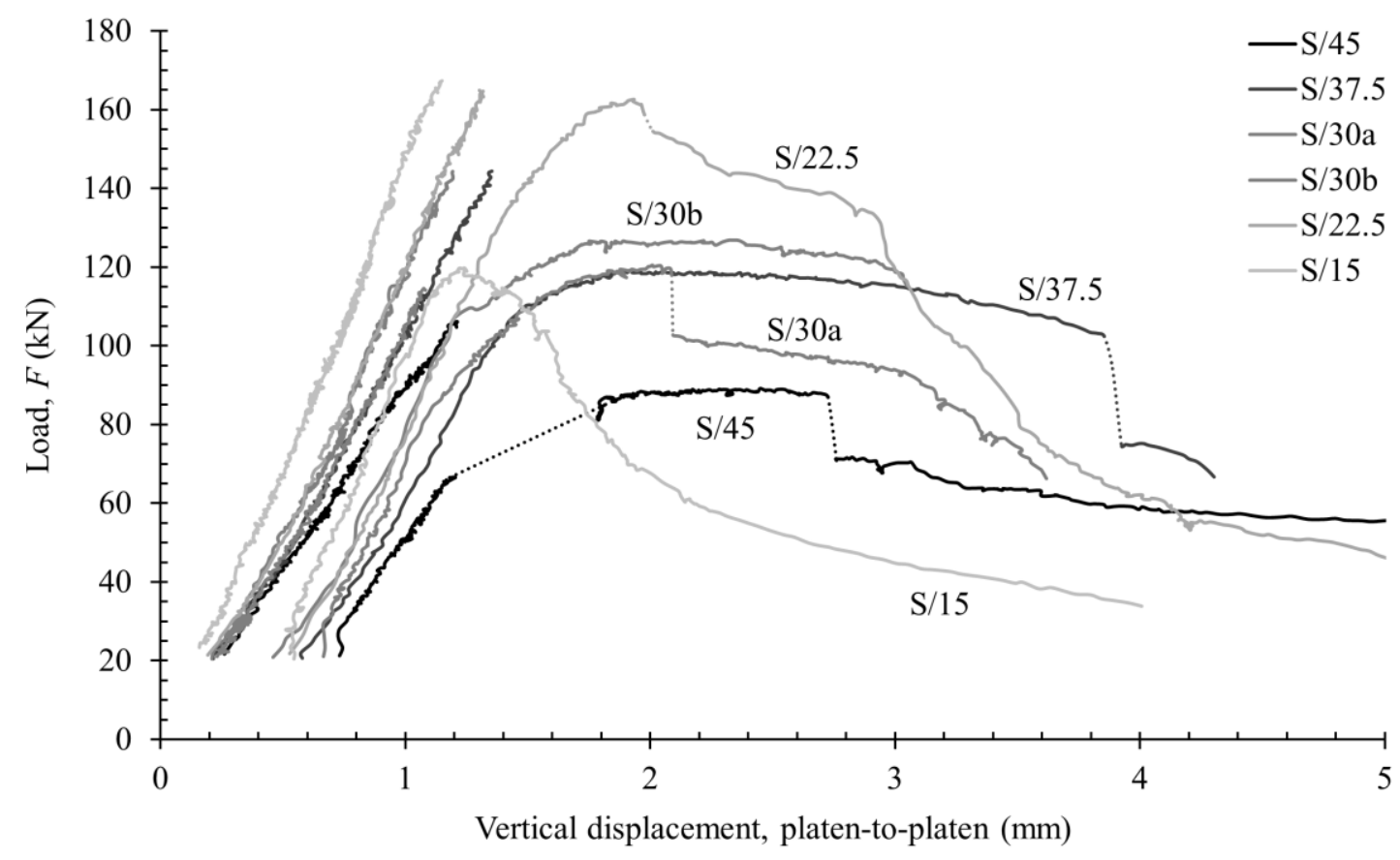

Figure 8.Load $F$ plotted against vertical displacement of the whole specimen measured platen-to-platen (unloading phase omitted for clarity)

The experimental results are summarised in Table 2. Stresses $\tau_{u}$ and $\sigma_{u}$ are the nominal shear and normal stresses on the interface at $F_{u}$. The stress $\sigma_{u, s v}$ is the restraining stress on the interface provided by the steel reinforcement, calculated from the strains measured by the strain gauges on the steel 
Authors' accepted version - Foster, R.M., Haria, S., Morley, C.T. and Lees, J.M. (2017) "Shear Capacity of Reinforced Concrete Subjected to Tension: Experimental Results and Analysis", J. Struct. Eng., 143(9), 04017085, http://dx.doi.org/10.1061/(ASCE)ST.1943-541X.0001819

390 reinforcement at $F_{u}$. The stresses $\tau_{u, c r}, \sigma_{u, c r}$ and $\sigma_{u, c r, s v}$ are the corresponding stresses at $F_{u, c r}$. Note that

391 tension is denoted -ve. The concrete compressive cylinder strength $f_{c}$ is determined as:

$f_{c}=0.8 f_{c u}$

Equation 26

392

393

394

395

396

397

398

399

400

\begin{tabular}{lcccccc}
\hline Specimen & $\begin{array}{c}F_{u} \\
{[\mathrm{kN}]}\end{array}$ & $\tau_{u} / f_{c}$ & $\left(\sigma_{u+} \sigma_{u, s v}\right) / f_{c}$ & $\begin{array}{r}F_{u, c r} \\
{[\mathrm{kN}]}\end{array}$ & $\tau_{u, c r} / f_{c}$ & $\left(\sigma_{u, c r+} \sigma_{u, c r, s v}\right) / f_{c}$ \\
\hline S/45 & 106.2 & 0.037 & -0.034 & 75.0 & 0.031 & 0.002 \\
S/37.5 & 144.4 & 0.044 & -0.031 & 119.0 & 0.037 & -0.002 \\
S/30a & 114.6 & 0.043 & -0.023 & 120.5 & 0.045 & 0.003 \\
S/30b & 144.3 & 0.047 & -0.026 & 126.9 & 0.041 & 0.002 \\
S/22.5 & 164.9 & 0.061 & -0.024 & 162.6 & 0.060 & 0.002 \\
S/15 & 167.3 & 0.071 & -0.019 & 119.8 & 0.051 & 0.004 \\
\hline
\end{tabular}

402

Since the steel in these tests is observed not to yield prior to $F_{u}$, it would be inappropriate to assume a restraint stress due to the reinforcement of $\rho_{s v} f_{y v}$ for the uncracked condition. The reinforcement

Table 2: Test results, note that tension is denoted -ve parameter $\psi$ is thus replaced with a $\psi^{\prime}$ leading to a revised restraint stress parameter $\psi^{\prime *}$ based on the actual reinforcement stress $\sigma_{s v}$ in cases where reinforcement has not yielded at peak load and noting that for this arrangement the force $N$ normal to the interface due to the specimen geometry is $F \sin \theta$ : 
Authors' accepted version - Foster, R.M., Haria, S., Morley, C.T. and Lees, J.M. (2017) "Shear Capacity of Reinforced Concrete Subjected to Tension: Experimental Results and Analysis", J. Struct. Eng., 143(9), 04017085, http://dx.doi.org/10.1061/(ASCE)ST.1943-541X.0001819

$\psi^{\prime}=\frac{\rho_{s v} \sigma_{u, s v}}{f_{c}}$

Equation 27

$\psi^{\prime *}=\psi^{\prime}+\frac{N}{A f_{c}}$

Equation 28

407 While the introduction of $\sigma_{s v}<f_{y v}$ may appear incongruous with respect to a plastic analysis, it must

408 be recognised that the upper bound theorem of plasticity is used here to evaluate the stress state causing failure at the concrete interface. The push-off test results are used to obtain measured combinations of shear and normal stresses at the interface at failure for the purposes of verification of

411 the plastic analysis. Knowledge of $\sigma_{s v}$, inferred from the strain gauge readings provides the magnitude

412 of the restraint stress normal to the interface at failure. In fact, the small strains measured in the

413 reinforcement at $F_{u}$, i.e. prior to cracking, mean that the use of $\sigma_{s v}$ has little effect on the analysis in

414 the cases considered here. More generally, whether it is reasonable in design to assume yielding of the reinforcement for a given combination of applied normal and shear stresses prior to failure such that $f_{y v}$ may be used for the purposes of calculating the restraint stress component is an important question and may depend on the particular case considered. However, the absence of yielding prior to peak uncracked load in many of the specimens tested as part of this study indicates that this assumption would not be reasonable where an interface is considered as uncracked in the presence of tension. This indicates that in the presence of net normal tension, the uncracked capacity of a concrete should not be superposed with a steel reinforcement contribution that assumes yielding of the reinforcement.

Figure 9 shows the existing range of push-off test results, with the addition of the uncracked modified push-off tests with tension as a result of $-v e$ angles of $\theta$. A relatively good agreement is seen between the push-off test results for shear and coexisting net tension, with the predictions of the plastic analysis adopting the effectiveness factors proposed by Chen (1988).

426 Although the effectiveness factors proposed by Chen (1988) have been shown to provide relatively good agreement, the comparison with an expanded set of push-off tests reported subsequently in the literature, and the new modified push-off test results, indicate that new effectiveness factors may be appropriate. For a concrete effectiveness factor in compression of $v=0.6$; and concrete effectiveness 
Authors' accepted version - Foster, R.M., Haria, S., Morley, C.T. and Lees, J.M. (2017) "Shear Capacity of Reinforced Concrete Subjected to Tension: Experimental Results and Analysis", J. Struct. Eng., 143(9), 04017085, http://dx.doi.org/10.1061/(ASCE)ST.1943-541X.0001819

430 factors in tension of $v_{t}=0.045$ for uncracked concrete, and $v_{t}=0$ and $v_{s}=0.5$ for cracked concrete,

431 the plastic predictions are shown in Figure 10. These values eliminate almost all of the unconservative

432 predictions while closely following the pattern of results. For heavily reinforced specimens or those

433 with high applied normal stresses, i.e., $\psi^{\prime *}$ greater than approximately 0.2 , the results are consistently

434 under predicted.

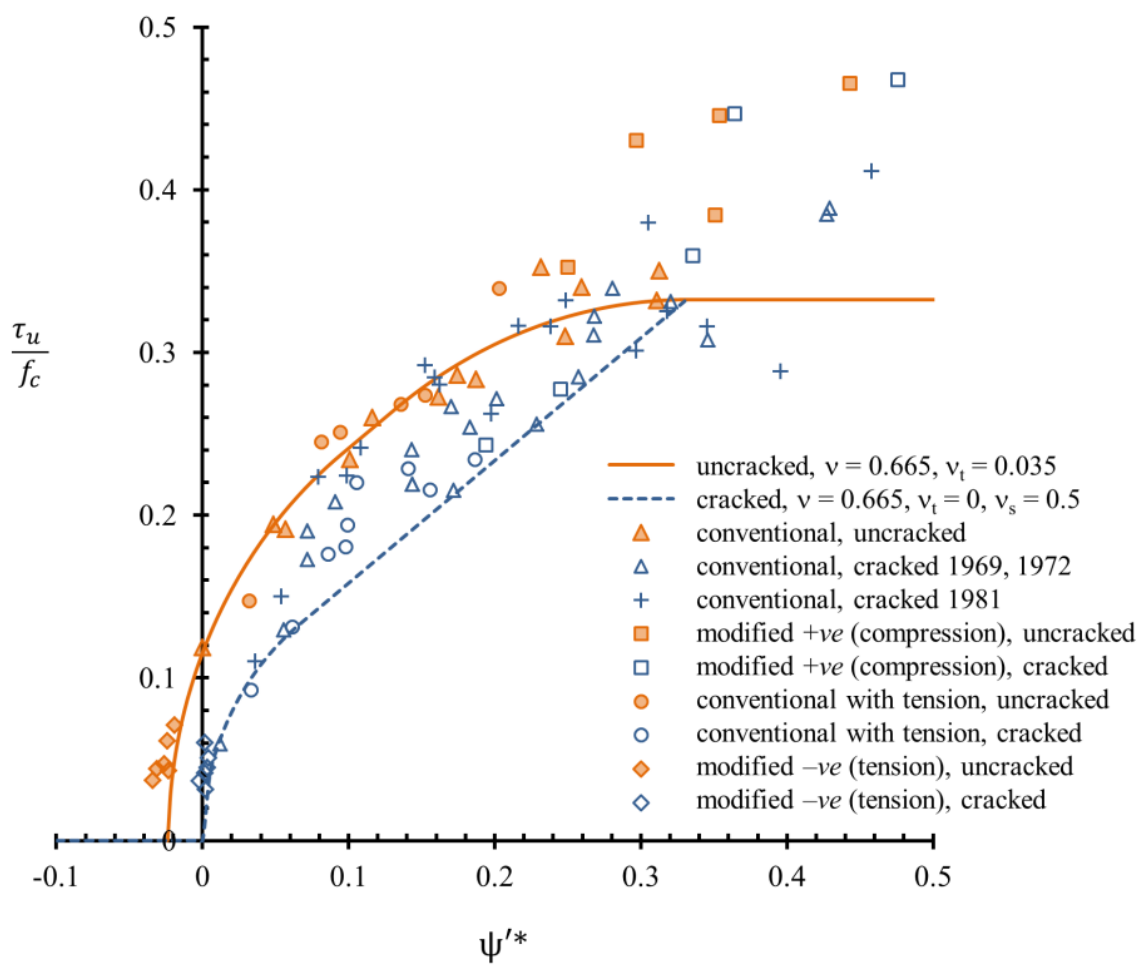

Figure 9. Uncracked analysis following the proposed $v$ and $v_{t}$ values of Chen (1988), and the commensurate results obtained in this study

439 It should be noted that the push-off tests reported in the literature and in this investigation cover only

440 a limited range of sizes of shear plane. Since the plastic analysis presented does not explicitly consider

441 the effect of shear plane size, further experimental work is required in order to determine whether the

442 effectiveness factors indicated by the test results considered here are applicable to larger concrete interfaces of a similar type. 
Authors' accepted version - Foster, R.M., Haria, S., Morley, C.T. and Lees, J.M. (2017) "Shear Capacity of Reinforced Concrete Subjected to Tension: Experimental Results and Analysis", J. Struct. Eng., 143(9), 04017085, http://dx.doi.org/10.1061/(ASCE)ST.1943-541X.0001819

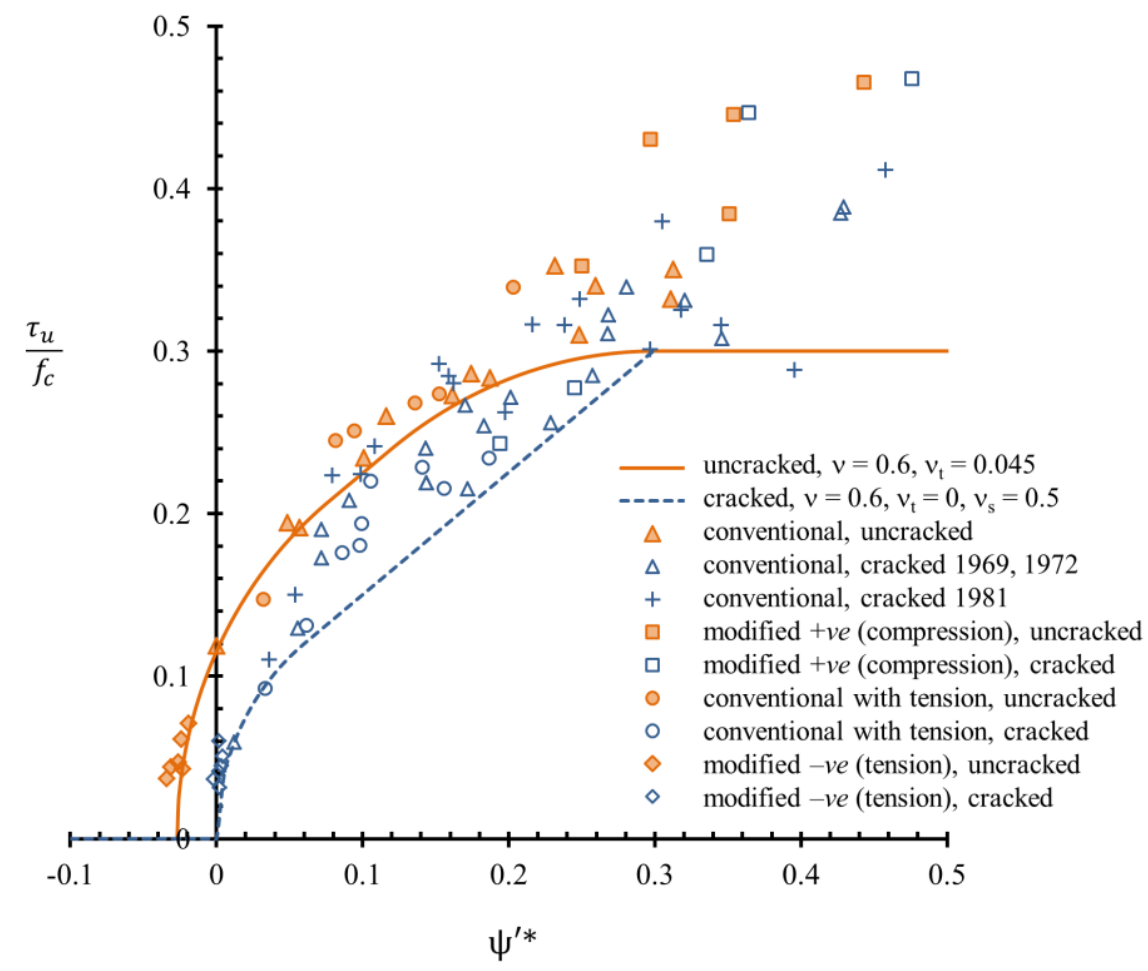

Figure 10. Uncracked and cracked analysis considering the proposed $v$ and $v_{t}$ values compared with a range of push-off test results in the literature and the new modified with tension results obtained in this study

\section{SUMMARY AND CONCLUSIONS}

448 A series of modified push-off tests with a range of $-v e$ angles $\theta$ were carried out in order to

449 investigate the effect of varying combinations of shear and normal tension across a joint or interface

450 in reinforced concrete. These tests, in conjunction with a number of tests reported in the literature were compared with the results of an analysis based upon the upper bound theorem of plasticity for interfaces in reinforced concrete. The following conclusions are indicated by the results of this study:

1. Modified push-off testing with varying $-v e$ angles $\theta$ provides an effective method for investigating the effect of combined shear and tension stresses on the capacity of a joint or interface in reinforced concrete.

2. A plastic analysis based upon the upper bound theorem of plasticity provides a promising method for evaluation of the strength of both cracked and uncracked interfaces in reinforced concrete subject to combined shear and normal stresses. The modified push-off test results 
Authors' accepted version - Foster, R.M., Haria, S., Morley, C.T. and Lees, J.M. (2017) "Shear Capacity of Reinforced Concrete Subjected to Tension: Experimental Results and Analysis", J. Struct. Eng., 143(9), 04017085, http://dx.doi.org/10.1061/(ASCE)ST.1943-541X.0001819 presented here provide an empirical verification of the application of the theory to interfaces subject to combined shear and tension.

3. The push-off test results indicate that a concrete effectiveness factor in compression of $v=$ 0.6; and concrete effectiveness factors in tension of $v_{t}=0.045$ for uncracked concrete and $v_{t}=$ 0 for cracked concrete may be appropriate for plastic analysis.

4. For interfaces subject to quite high levels of restraint, i.e. approximately $\psi^{\prime *}>0.3$, capacity is often considerably under predicted by the plastic analysis using the effectiveness factors suggested by this study.

\section{ACKNOWLEDGEMENTS}

The authors wish to gratefully acknowledge the financial support of the UK Engineering and Physical Sciences Research Council (EPSRC) through grant EP/I018972/1. The authors also wish to extend their sincere thanks to the staff of the University of Cambridge Structures Research Lab for their invaluable assistance in carrying out the experimental work reported above. Additional data related to this publication is available at the University of Cambridge institutional data repository: [https://doi.org/10.17863/CAM.8477]

\section{REFERENCES}

AASHTO (American Association of State Highway Transportation Officials) (2008). 'Bridging the Gap: Restoring and Rebuilding the Nation's Bridges', Washington D.C.

ACI (American Concrete Institute) (2014). "Building Code Requirements for Structural Concrete and Commentary", ACI 318-14, Farmington Hills, USA

Birkeland, P. W. and Birkeland, H. W. (1966) 'Connections in Precast Concrete Construction’ J. Am. Concrete I., Proc., 63(3), pp. 345-368.

BSI (2004), EN 1992-1-1:2004 'Design of Concrete Structures. General Rules and Rules for Buildings', BSI, London, UK 
Authors' accepted version - Foster, R.M., Haria, S., Morley, C.T. and Lees, J.M. (2017) "Shear Capacity of Reinforced Concrete Subjected to

Tension: Experimental Results and Analysis", J. Struct. Eng., 143(9), 04017085, http://dx.doi.org/10.1061/(ASCE)ST.1943-541X.0001819

Chen, G. (1988) 'Plastic Analysis of Beams, Deep Beams and Corbels', Structural Research Lab Report No. R-237, Technical University of Denmark, Copenhagen

Foster, R.M., Morley, C.T. and Lees, J. M. (2016) 'Modified Push-Off Testing of an Inclined Shear Plane in Reinforced Concrete Strengthened with CFRP Fabric.' J. Compos. Constr., 20(3), 04015061, 10.1061/(ASCE)CC.1943-5614.0000623

Gouvernement du Québec (2007), Commission of Inquiry into the Collapse of a Portion of the de la Concorde Overpass October 3, 2006 - October 15, 2007: Report, Gouvernement du Québec

Hanson, N.W. (1960) 'Precast Prestressed Concrete Bridges 2: Horizontal Shear Connections', Journal of the PCA Research and Development Laboratories, Vol. 2, No. 2, pp. 38-58

Highways Agency (2003) Technical Audit of the Application of BA79: A Review Of Bridge Assessment Failures on the Motorway and Trunk Road Network [prepared by Shave, J., Denton, S.R. and Charlton, M.], Highways Agency: Dorking

Hofbeck, J.A, Ibrahim, I.O. \& Mattock, A.H. (1969) 'Shear Transfer in Reinforced Concrete', Journal of the American Concrete Institute: Proceedings, Vol. 66, No. 2, pp. 119-128

Ibell, T.J., Morley, C.T. and Middleton, C.R. (1997) 'A Plasticity Approach to the Assessment of Shear in Concrete Beam and Slab Bridges', The Structural Engineer, Vol. 75, No. 19, pp. 331338

Ibell, T. \& Burgoyne, C. (1999) 'Use of Fiber-Reinforced Plastics Versus Steel for Shear Reinforcement of Concrete', ACI Structural Journal, Vol. 96, No. 6, pp. 997-1002

Jensen, B.C. (1977) 'Some Applications of Plastic Analysis to Plain and Reinforced Concrete', Institute of Building Design Report No. 123, Technical University of Denmark, Copenhagen

Mattock, A. H. and Hawkins, N. M. (1972). 'Shear Transfer In Reinforced Concrete - Recent Research' J. PCI, Vol. 17, No. 2, pp. 55-75. 
Authors' accepted version - Foster, R.M., Haria, S., Morley, C.T. and Lees, J.M. (2017) "Shear Capacity of Reinforced Concrete Subjected to

Tension: Experimental Results and Analysis", J. Struct. Eng., 143(9), 04017085, http://dx.doi.org/10.1061/(ASCE)ST.1943-541X.0001819

Mattock, A.H., Johal, L. and Chow, H.C. (1975) "Shear Transfer in Reinforced Concrete with Moment or Tension Acting Across the Shear Plane" J. PCI, Vol. 20, No. 4, pp. 76-93.

Middleton, C.R. (2004) 'Bridge Management and Assessment in the UK' Proceedings of Austroads 5th Bridge Conference, Austroads, Australia, 16.

Neville, A.M. (2011) Properties of Concrete (5th Ed.), Harlow: Pearson Education Limited

Nielsen, M.P. and Hoang, L.C. (2011) Limit Analysis and Concrete Plasticity (3rd Ed.), CRC Press: London

Santos, P.M.D. \& Julio, E.N.B.S. (2012) ‘A State-of-the-art Review on Shear-friction', Engineering Structures, Vol. 45, pp. 435-448, http://doi.org/10.1016/j.engstruct.2012.06.036

Shave, J.D., Ibell, T.J. and Denton, S.R. (2007) 'Shear Assessment of Reinforced Concrete Bridges with Short Anchorage Lengths', The Structural Engineer, Vol. 85, No. 5, pp. 30-37

Walraven, J.C. and Reinhardt, H.W. (1981) 'Theory and Experiments on the Mechanical Behaviour of Cracks in Plain and Reinforced Concrete Subject to Shear Loading' Heron, No. 26, Vol. 1, pp. $1-68$.

Zhang, J-P. (1997) 'Strength of Cracked Concrete, Part 2 -Micromechanical Modelling of Shear Failure in Cement paste and in Concrete', Structural Research Lab Report No. R-17, Technical University of Denmark, Copenhagen 
Authors' accepted version - Foster, R.M., Haria, S., Morley, C.T. and Lees, J.M. (2017) “Shear Capacity of Reinforced Concrete Subjected to Tension: Experimental Results and Analysis", J. Struct. Eng., 143(9), 04017085, http://dx.doi.org/10.1061/(ASCE)ST.1943-541X.0001819

524

525

526 